\title{
CERVANTES Y EL PODER DE LA NARRACIÓN
}

Hasta el octavo capítulo de Don Quijote, el lector cree que hay una sola trama, la de las hazañas del protagonista. En el octavo capítulo, otra trama se presenta. En la mitad de la acción, se corta la narración porque el narrador ya no tiene más información de los archivos de la Mancha. Con esta interrupción, Cervantes lleva la atención del lector a una segunda trama -la del proceso de escribir una novela, en particular esta novela, El ingenioso hidalgo don Quijote de la Mancha.

¿Por qué introduce Cervantes esta segunda trama de esta manera en vez de presentarla al principio del libro? Presentándola de esta manera hace un juego. Cuando el lector está completamente envuelto en la primera trama, Cervantes nos recuerda que lo que estamos leyendo no es la verdad. Es un libro, y además, uno que ha sido traducido del árabe. El hecho de la traducción del libro es importante por dos razones: primero, sabemos que los moros están inclinados a mentir, y segundo, es difícil para cualquier traductor hacer una traducción fidedigna.

El primer hecho, que los árabes tienen una predisposición para mentir, se presenta por las palabras del segundo narrador. Hablando de los árabes, dice que es «muy propio de los de aquella nación ser mentirosos» (I-9, pág. 103). La segunda razón, que ninguna traducción puede capturar completamente la obra original, se expone cuando don Quijote está visitando la imprenta. El usa la siguiente metáfora, a...el traducir de una lengua en otra, como no sea de las reinas de las lenguas, griega y latina, es como quien mira los tapices flamencos por el revés, que aunque se veen las figuras, son lle- 
nas de hilos que las escurecen, y no se veen con la lisura y tez de la haz» (II-62, pág. 1027).

Esta segunda trama, el juego de narradores, tiene mucho que ver con la primera trama, las hazañas de don Quijote. En las dos hay una preocupación con el tema de cómo escribir o narrar una historia. Don Quijote es un hombre que se vuelve loco porque pone demasiada fe en lo que ha leído. El propósito de Cervantes se expresa en las palabras de su «amigo» con quien habla en el Prólogo, «...esta vuestra escritura no mira a más que a deshacer la autoridad y cabida que en el mundo y en el vulgo tienen los libros de caballerías» (I-Prólogo, pág. 18).

Leo Spitzer cree que la atención crítica no se ha enfocado bastante en este propósito de Cervantes. Él supone que los críticos no han visto la profundidad de tal propósito. Dice Spitzer que «lo que hizo Cervantes fue SENTAR EL PROBLEMA DEL LIBRO, y de su influencia sobre la vida” (390). Para una novela con este propósito, cierta técnica se necesita que Spitzer describe así, «[La novela] tiene que permitir que la historia se desenvuelva como si lo hiciera para el disfrute del lector crédulo, sugiriendo astutamente al mismo tiempo la reacción del autor crítico» (392).

La segunda trama del libro, la del juego de narradores, se desarrolla en lo que se llama el nivel del «récit», y la primera trama se desarrolla en el nivel «diegético». (Estos términos fueron introducidos por Genette y los críticos los han adoptado.) En el nivel diegético hay la misma preocupación con las cuestiones de narración que vemos en el nivel del récit.

Concentrándonos primero en el nivel del récit, es interesante observar los comentarios que Cide Hamete hace en los márgenes del texto. Lo primero que el segundo narrador aprende sobre el nivel narrativo de Cide Hamete viene de un comentario en el margen, «Esta Dulcinea del Toboso, tantas veces en esta historia referida, dicen que tuvo la mejor mano para salar puercos que otra mujer de toda la Mancha» (I-9, pág. 102). Luego, en el nivel narrativo dice el segundo narrador que Cide Hamete atiene para sí ser tan locos los burladores como los burlados, y no estaban los duques dos dedos de parecer tontos, pues tanto ahínco ponían en burlarse de dos tontos» (II-70, pág. 1071).

De estos comentarios de Cide Hamete vemos que él tiene un buen sentido del humor y sus propias opiniones sobre los personajes. Esta observación plantea dos preguntas: la primera, ¿cuántas veces hay tales comentarios, o en el margen o en el texto, que el traductor y el segundo narrador pasan por alto? La segunda pregunta es si las opiniones que Cide Hamete tiene con respecto a los personajes han influido su narración de la historia. ¿Enfatiza él 
ciertos detalles que conforman con sus opiniones sobre los personajes y pasa por alto otros detalles que no conforman?

Además de comentarios de Cide Hamete que el traductor y el segundo narrador pasan por alto, hay partes de la narración misma que ellos juzgan innecesarios y no incluyen en la traducción. El segundo narrador dice que todos los lectores deben agradecer a Cide Hamete «la curiosidad que tuvo en contarnos las semínimas della, sin dejar cosa, por menuda que fuese, que no la sacase a la luz distintamente» (II-40, pág. 849). Pero más temprano este narrador había dicho, «Aquí pinta el autor todas las circunstancias de la casa de don Diego, pintándonos en ellas lo que contiene una casa de un caballero labrador y rico; pero al traductor desta historia le pareció pasar estas y otras semejantes menudencias en silencio, porque no venían bien con el propósito principal de la historia” (II-18, pág. 687).

Parece que las preguntas sobre lo que sabemos de la historia de don Quijote y lo que no sabemos por culpa del autor, traductor o narrador sirven un propósito central para Cervantes -recordar al lector que nunca podemos fiarnos completamente de un autor. Cada autor escribe desde su punto de vista, y cada libro tiene que ser leído con cuidado.

En el nivel diegético también vemos advertencias sobre el cuidado que debemos tener como lectores $u$ oyentes de un cuento. Después de oir la historia de Grisóstomo y Marcela desde el punto de vista de los amigos de Grisóstomo, pensamos que Marcela es cruel y ha engañado a Grisóstomo. Pero después de oir la historia desde el punto de vista de la misma Marcela, ya no sabemos en quien poner la culpa por la muerte de Grisóstomo, pero es evidente que la culpa no es de ella.

Otra cosa en el nivel diegético que refleja esta preocupación con el asunto de narración es que algunas de las historias intercaladas se interrumpen de la misma manera que se interrumpe la narración del Ingenioso hidalgo. La primera vez que esto sucede en el nivel diegético es cuando Sancho está contando una historia a don Quijote, y don Quijote lo interrumpe, le hace perder la cuenta de cuántas cabras habían pasado y Sancho dice a don Quijote que ya no puede seguir con la historia (I-20, págs. 198-199). La segunda vez que hay una interrupción en una historia es con la de Cardenio. Cuando Cardenio menciona el libro Amadís de Gaula, don Quijote no puede resistir hablar sobre los libros de caballerías, y Cardenio no sigue con su narración porque vuelve a su locura (I-24, págs. 247-249).

Estas interrupciones sirven la misma función que las interrupciones en el nivel del récit. Cuando estamos perdidos dentro de una 
historia, sea la historia de don Quijote o sea alguna de las historias intercaladas, Cervantes nos recuerda que estamos dentro de una ficción y no nos debemos perder. A veces esta interrupción interfiere con el gozo que el lector ha tenido en la historia interrumpida -no sabemos el fin de la historia de Sancho, y don Quijote no oyó el fin de la historia de Cardenio. Pero tenemos que acordarnos de lo que Cervantes está escribiendo. No es una novela de caballerfas, sino lo que Spitzer llama una contranovela, o una novela critica. Spitzer elabora su definición de la contranovela así: «Una crítica de un género literario condenado por el autor, escrita en forma de novela paródica que, de manera parasitaria, tuvo que adoptar todas las situaciones y recursos del tipo de novela que ridiculizabax (392). Para una contranovela, no está mal que el lector goce de la lectura, y aun es necesario. Pero a veces este gozo tiene que sacrificarse a un fin más alto, que es aprender cómo debemos leer una novela.

El curioso impertinente aparece dentro de la narración del Quijote como contraste -es una novela en la cual no hay digresiones, y hay solamente una interrupción. ¿Por qué pone Cervantes esta novela dentro del Quijote? (cosa por la cual ha sido criticado bastante). La novela del Curioso impertinente gusta a quien la lee, incluso al cura, a pesar de sus críticas. ¿Escribe Cervantes esta novela y la pone dentro del Quijote como ejemplo de lo que está criticando en la contranovela? Tal vez él siente un peligro, especialmente en una novela con tanta verosimilitud psicológica, para el lector crédulo.

En El curioso impertinente vemos algo parecido a la narración de una historia, que es un «drama inventado» para usar la terminologfa de Ruth El Saffar (294). En el drama inventado por Anselmo, Lotario representa el papel de un enamorado de Camila, esposa de Anselmo. Pero, como observa El Saffar, «...todo el artificio puede derrumbarse al perder los personajes un sentido claro de la división entre sus papeles fingidos y los reales» (295). En el caso de Lotario, se enamora de veras de Camila y ya no está representando un papel.

Vemos otro ejemplo de cómo un drama inventado puede crear expectaciones verdaderas en la casa de los duques. La duquesa manda una carta a Teresa Panza para gastar una broma, pero la respuesta de Teresa nos muestra cuán grandes son las esperanzas que recibir la carta le dio. Al fin de su respuesta Teresa escribe: «No se le olvide a vuestra pomposidad de escribirme, que yo tendré cuidado de la respuesta, avisando de mi salud y de todo lo que hubiere que avisar deste lugar» (II-52, pág. 947). Teresa cree que en la duquesa ha encontrado a una amiga que hara lo que pueda para ayudarla a subir en la escala social. 
Esta relación entre un drama inventado y los resultados en el mundo real amplifica lo que se ha dicho sobre una novela o un cuento y sus consecuencias para el lector. Cervantes, que tiene tanta destreza para crear un mundo bello de ficción, no está satisfecho con hacerlo. Los juegos de narradores en los dos niveles nos presentan constantemente con la pregunta, ¿cuál es el propósito de un mundo bello en el cual nos perdemos? Don Quijote, desengañado, recobra su cordura perdida. Y sin su loca, pero bella, visión de la realidad, la muerte es mejor que la vida.

Si el mundo sin ilusiones es peor que la muerte, ¿por qué trata Cervantes de desengañarnos? Tal vez porque de todas maneras vamos a morir, y esa conciencia de la muerte lleva un deseo de saber la verdadera naturaleza de la vida.

\author{
LISA PRICE \\ Villanova University
}

\title{
BIBLIOGRAFIA
}

Cervantes, Miguel De. Don Quijote de la Mancha, ed. Martín de Riquer. Barcelona, Editorial Planeta, 1980.

El Saffar, Ruth SNODGRass. «La función del narrador ficticio en Don Quijote», en $E l$ «Quijote» de Cervantes, ed. George Haley. Madrid, Taurus Ediciones, 1980.

SPITZER, Leo. «Sobre el significado de Don Quijote», en El «Quijote» de Cervantes, ed. George Haley. Madrid, Taurus Ediciones, 1980. 